\title{
HIGH RESOLUTION ELECTRON ENERGY LOSS STUDIES OF SURFACE VIBRATIONS
}

\author{
Progress Report 1992 \\ for Ptriod June 1, 1991 - May 1, 1992 \\ L.L. Kesmodel \\ Indiana University \\ Bloomington, IN 47405
}

May 1992

Prepared for

THE U.S. DEPARTMENT OF ENERGY

AGREEMENT No. DE-FG02-84ER45147

\section{NOTICE}

This reporı was prepared as an account of work sponsored by the United States Government. Neither the United States nor the Department of Energy, nor any of their employees, nor any of their contractors, subcontractors, or their employees, makes any warranty, express or implied, or assumes any legal liability or responsibility for the accuracy, completeness, or usefulness of any information, apparatus, produc $\%$ or process disclosed or represents that its use would not infringe privately-owned rights. 


\section{ABSTRACT}

New experimental studies of surface vibrational properties of materials with highresolution electron energy loss spectroscopy (EELS) are reported. This document summarizes recent progress on surface phonon dispersion measurements on copper (001); silver (001) and (111); oxygen adsorption on ultrathin films of cobalt and nickel; aluminum on silicon (111); and copper-oxide based superconductors. 


\section{A. SUMMARY OF RESEARCH}

\section{Introduction}

The project is devoted to new experimental investigations of surface vibrational properties on clean metal, semiconductor and superconductor surfaces. Adsorbed layers including metal films on these materials are also of interest to the project. The principal experimental method employed for the measurement of surface phonon excitations and their dispersion is high-resolution electron energy loss spectroscopy (EELS). This section summarizes progress made since the last progress report (May 31,1991) to the time of this writing. Several publications have resulted this past year and are appended to this report or outlined below.

\section{Surface Phonons on $\mathrm{Cu}(001), \mathrm{Ag}(001)$ and $\mathrm{Ag}$ (111)}

A collaborative study with S.Y. Tong, K.M. Ho, K.P. Bohnen and co-workers was completed for the (001) surfaces and provides a very satisfactory explanation of the surface phonon dispersion in the context of first principles phonon calculations. A reprint is appended to this report [1].

We have recently obtained new EELS data on surface phonon dispersion on $\mathrm{Ag}$ (111), wherein the gap mode $\left(S_{2}\right.$ at $\left.\bar{M}\right)$ has been measured for the first time. This data is currently being analyzed in a collaboration with S.Y. Tong.

\section{Oxygen Adlayers on $\mathrm{Ni} / \mathrm{Cu}(001)$ and $\mathrm{Co} / \mathrm{Cu}(001)$ Thin Films}

The low frequency phonon modes associated with oxygen adsorption in $\mathrm{c}(2 \times 2)$ structures on ultrathin films of cobalt and nickel on a copper (001) substrate have been correlated with the film growth mechanism. The results are described in detail in the appended 
reprint [2].

\section{Surface Phonons on the $\mathrm{Al} / \mathrm{Si}(111)$ System}

As discussed in last year's report we have measured new phonon excitations associated with the $\sqrt{3} \times \sqrt{3}-R 30^{\circ}$ structure of aluminum adsorbed on $\mathrm{Si}$ (111). A reprint dealing with the specular electron scattering measurements at $\bar{\Gamma}$ is attached [3] and showed that our measurements were in excellent agreement with some of the theoretically predicted phonon frequencies. In order to gain a more complete understanding of the modes of this system we have measured the phonon dispersion for several modes in the $\bar{\Gamma}-\bar{K}$ direction (Fig. 1). Publication of these results with additional calculation is planned in the near future.

\section{Copper Oxide Based High Temperature Superconductors}

EELS has become an important technique for the study of the Cu-O-based high temperature (high $T_{c}$ ) superconductors [4]. Since EELS is highly sensitive to the first few atomic layers, the presence or absence of superconductivity in this surface region can be detected, and properties of the surface (e.g., the superconducting energy gap) can be compared with those of the bulk. Furthermore, the momentum carried by the electrons enables EELS to probe a range of momentum space not accessible with infrared spectroscopy.

We have constructed a liquid helium-cooled manipulator for the study of $\mathrm{Cu}$-O-based superconductors using EELS. The ultrahigh vacuum system in which the measurements are made is equipped with load-locking, permitting samples to be changed in less than an hour. This capability is important, since the properties of the high $T_{c}$ materials are known to depend strongly on fine details of the sample preparation, such as oxygen doping. The samples currently under investigation are large, oxygenated single crystals of $\mathrm{Bi}_{2} \mathrm{Sr}_{2} \mathrm{CaCu}_{2} \mathrm{O}_{8+x}(\mathrm{Bi}(2212))$ with $T_{c} \approx 85 \mathrm{~K}$ and a transition width of $\sim 2 \mathrm{~K}$. 
Preliminary spectra for $\mathrm{Bi}(2212)$ are shown in Figure 2. Spectrum a) exhibits prominent peaks at 49 and $80 \mathrm{meV}$. These peaks have been previously observed and are believed to correspond to oxygen vibrations [4]. A weaker third peak is evident near $24 \mathrm{meV}$. It is likely that this peak is also caused by a bulk phonon, but definitive assignment of the peak requires further measurements. Spectrum b) was measured at a different location on the same sample, and it exhibits very different behavior. Spectra such as this which exhibit low loss background and an absence of features have been associated with regions of the surface possessing high conductivity. The broad, hump-like feature observed in an earlier EELS study of high $T_{c}$ materials, and associated with the superconducting energy gap [4], is not evident in either of these spectra. This result suggests that this particular surface is not superconducting. The factors responsible for the presence or absence of superconductivity on the surface of these materials is presently an area of active research.

\section{B. PERSONNEL}

Graduate research assistants Lieming Chen and Prasad Akavoor were supported during the current grant period and are continuing on the project for their doctorate degrees. Dr. George Glander was supported as a postdoctoral associate until August, 1991, at which time he joined the faculty of Clarion University. Dr. Robert Phelps from the University of California at Berkeley joined the group as a postdoctoral associate in December of 1991.

$$
\text { Reprinits remored }
$$




\section{BIBLIOGRAPHY}

1. Y.Chen, S.Y. Tong, J.-S. Kim, L.L. Kesmodel, T.Rodach, K.P.Bohnen, and K.M. Ho, Phy.Rev. B 44, 11394 (1991).

2. J.-S. Kim, M.H. Mohamed and L.L. Kesmodel, Surf.Sci. 260, 185 (1992).

3. G.S. Glander, P. Akavoor and L.L. Kesmodel, Phys.Rev. B 44, 5893 (1991).

4. J.E. Demuth, B.N.J. Persson, F. Holtzberg, and C.V. Chandrasekhar, Phys. Rev. Lett. 64, 603 (1990); B.N.J. Persson and J.E. Demuth, Phys. Rev. B 42, 8057 (1990). 


\section{RECENT PUBLICATIONS ASSOCIATED WITH GRANT}

1. Vibrational Spectroscopy of Ordered Oxygen Adlayers on $\mathrm{Ni} / \mathrm{Cu}(001)$ and $\mathrm{Co} / \mathrm{Cu}$ (001) Thin Film Systems, J.-S. Kim, M.H. Mohamed and L.L. Kesmodel, Surf. Sci. 260, 185 (1992).

2. High-Resolution Electron Energy Loss Studies of Al Adsorption on Si (111), G.S. Glander, P. Akavoor and L.L. Kesmodel, Phys. Rev. B 44, 5893 (1991).

3. Characterization of Surface Phonons on $\mathrm{Cu}$ (001) and Ag (001): First-Principles Phonon Calculations with Experimental and Theoretical Studies of High-Resolution Electron Energy Loss Spectra, Y. Chen, S.Y. Tong, J.-S. Kim, L.L. Kesmodel, T. Rodach, K.P. Bohnen and K.M. Ho, Phys. Rev. B 44, 11394 (1991). 
E. FIGURES

Fig. 1: Dispersion of low frequency phonon vibrations $(\bar{\Gamma}-\bar{K})$ for aluminum adsorption on silicon (111).

Fig. 2: EELS spectra for Bi(2212) exhibiting a) phonon excitations and b) low background spectrum associated with high-conductivity region. 


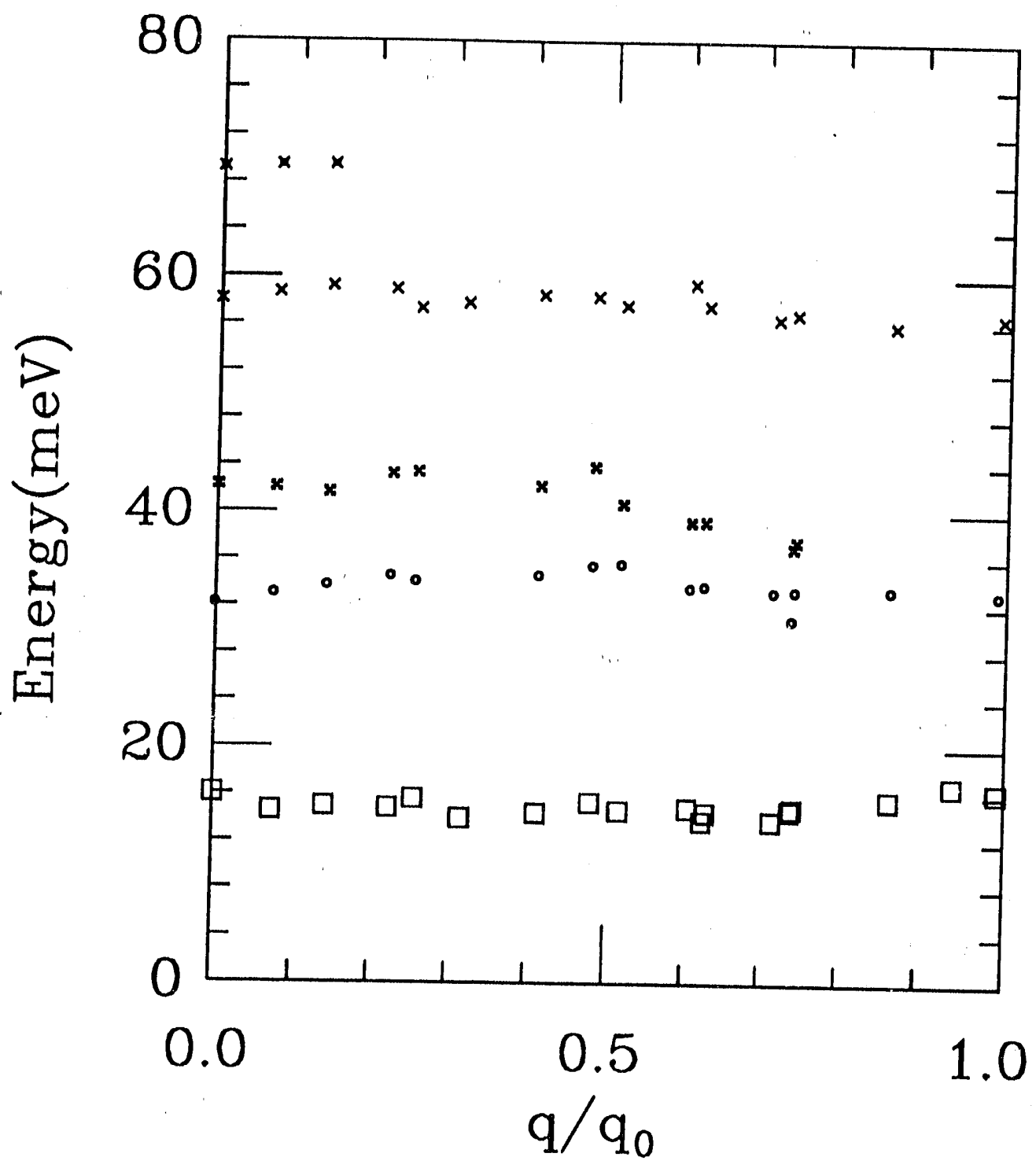

F1gure 1 


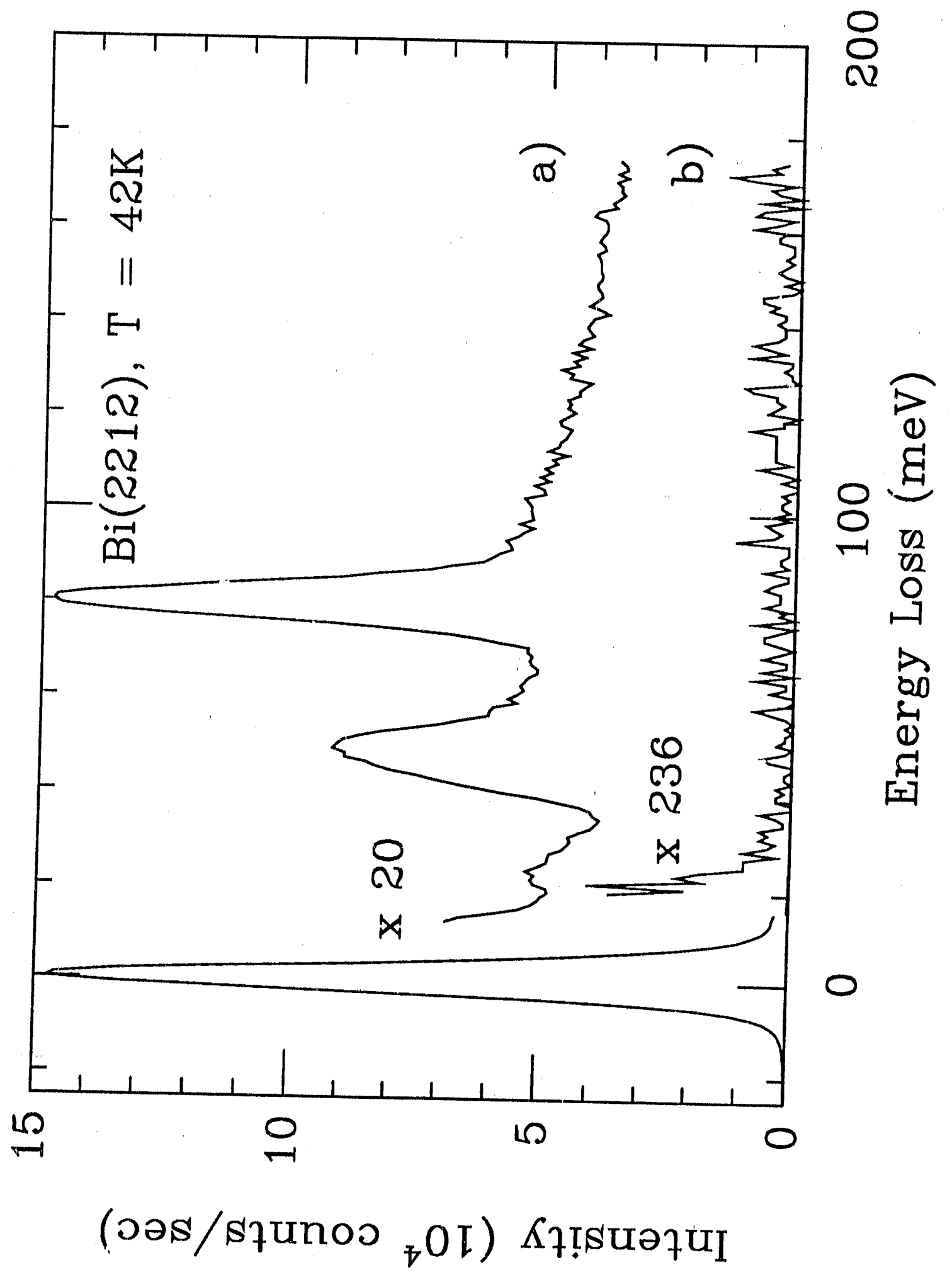



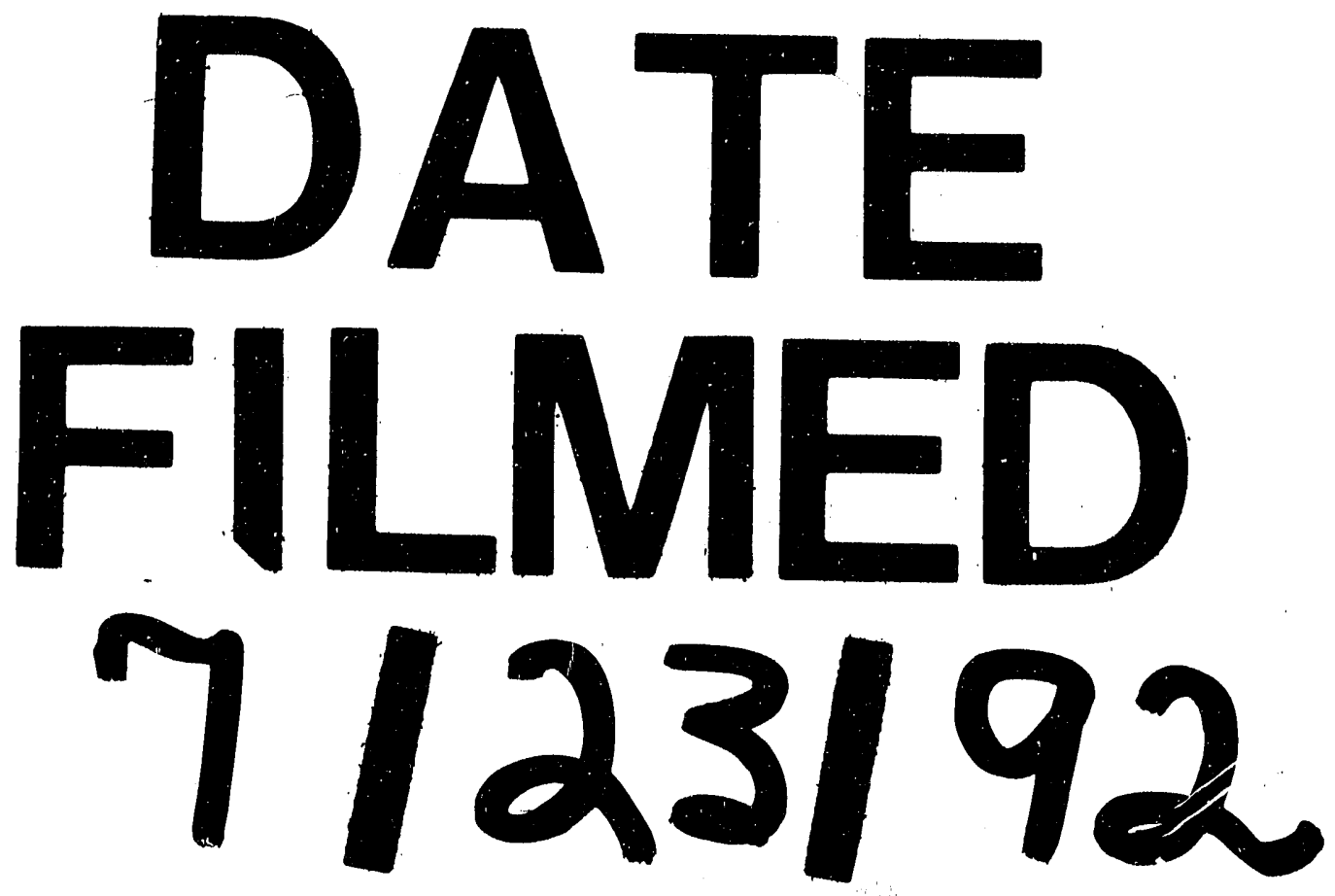
